\title{
CEPBИC / SERVICES
}

УДК 338.46

DOI: $10.22412 / 1993-7768-11-4-8$

\section{Развитие малого бизнеса в сфере потребительского рынка и услуг как фактор экономического роста (на материалах Республики Хакасия)}

\author{
Кочеткова Елена Николаевна*, кандидат экономических наук, доцент, ken.78@mail.ru, \\ Трусова Светлана Васильевна*, кандидат экономических наук, доцент, sertrus@mail.ru, \\ * Институт экономики и управления, Хакасский государственный университет им. Н.Ф. Катанова,
} г. Абакан, Республика Хакасия, Российская Федерация

\begin{abstract}
Аннотация. Данная статья посвящена сущности и роли малого бизнеса в сфере потребительского рынка и услуг как важного условия роста экономики. В статье представлен анализ состояния малого бизнеса в субъекте РФ - Республики Хакасия, подведены некоторые итоги его развития, исследована структура малого бизнеса по числу предприятий в различных видах деятельности. Дана оценка организации малого бизнеса в сфере потребительского рынка и услуг. Представлены особенности и проблемы развития предпринимательских структур в ссрере потребительского рынка и услуг на уровне региона (на примере Республики Хакасия). Потребительский рынок остается одним из важных факторов экономического роста в Республике Хакасия. Определены факторы, способствующие развитию малого бизнеса на региональном уровне и их влияние на экономический рост. Отмечено, что именно малые предприятия, не требующие крупных стартовых инвестиций и гарантирующие высокую скорость оборота ресурсов, способны наиболее быстро решать проблемы фрормирования и насыщения рынка товарами и услугами. Малые предприятия способны оперативно реагировать на изменение потребительского спроса и за счет этого обеспечивать необходимое равновесие на потребительском рынке. Данное исследование ограничено территорией Республики Хакасия, тем не менее, информация может быть применена и использована в других регионах Российской Федерации, а также при подготовке учебных пособий и статей.

Ключевые слова: Малый и средний бизнес, предпринимательство, потребительский рынок, сфера услуг, торговля, экономика, экономический рост, экономическая деятельность, экономическая политика

Для цитирования: Кочеткова Е.Н., Трусова С.В. Развитие малого бизнеса в сфере потребительского ранка и услуг как фрактор экономического роста (на материалах Республики Хакасия) // Сервис plus. T. 11. 2017. № 4. C. 78-92. DOI: 10.22412/1993-7768-11-4-8.
\end{abstract}

Статья поступила в редакцию: 25.09.2017.

Статья принята к публикации: 26.09.2017.

\section{The development of small business in the sphere of consumer market and services as a factor of economic growth (on materials of the Republic of Khakassia)}

Elena N. Kochetkova*, Cand. Sc. (Economics), Associate Prof., ken.78@mail.ru, Svetlana V. Trusova*, Cand. Sc. (Economics), Associate Prof., sertrus@mail.ru

\footnotetext{
* Institute of economics and management, Khakassian State University named after N.F. Katanov, Abakan, Republic of Khakassia, Russian Federation
} 
Кочеткова Е.Н., Трусова С.В. Развитие малого бизнеса в сфере потребительского ранка и услуг как фактор экономического роста (на материалах Республики Хакасия)

Kochetkova E.N., Trusova S.V., The development of small business in the sphere of consumer market and services as a factor of economic growth (on materials of the Republic of Khakassia)

\section{Abstract}

This article focuses on the nature and role of small business in the sphere of consumer market and services as an important condition of economic growth. The article presents the analysis of the state of small business in the federal subjects of Russia - the Republic of Khakassia, and summarizes its development, the structure of small business by the number of enterprises in different activities. The authors estimate the small business in the sphere of consumer market and services and present the peculiarities and problems of development of entrepreneurial structures in the sphere of consumer market and services at the regional level (on the example of Republic of Khakassia). The consumer market remains one of the most important factors of economic growth in the Republic of Khakassia. The authors determine the factors contributing to the development of small business on regional level and their impact on economic growth. They note that just small businesses do not require large upfront investment and guaranteeing a high rate of turnover of resources and they can most quickly solve the problems of the formation and saturation of market with goods and services. Small businesses can quickly respond to changing consumer demand and thus they can provide the necessary balance in the consumer market. This study is limited to the territory of the Republic of Khakassia, however, the information can be applied and used in other regions of the Russian Federation, as well as in the preparation of textbooks and articles.

Keywords: Small and medium business, entrepreneurship, consumer market, services, trade, economy, economic growth, economic activity, economic policy

For citation: Kochetkova E.N., Trusova S.V., The development of small business in the sphere of consumer market and services as a factor of economic growth (on materials of the Republic of Khakassia). Servis plus, vol. 11, no. 4, 2017, pp. 78-92. DOI: 10.22412/1993-7768-11-4-8.

Submitted: $2017 / 09 / 25$

Accepted: 2017/09/26.

\section{Введение}

Роль потребительского рынка и услуг в современной экономике обусловлена тем, что в этом секторе, как и в других секторах малого бизнеса, формируются основополагающие фракторы экономического роста. Важными становятся масштабные структурные изменения в отраслях ссреры потребительского рынка и услуг, имеющие важнейшее значение для дальнейшего развития экономики и повышения качества жизни населения.

Сектор потребительского рынка и услуг - первый шаг в бизнес, начав с которого можно стать серьезным бизнесменом. Самым доступным видом бизнеса сегодня, на наш взгляд, являются бизнес-идеи в ссрере услуг. Основная доля в развитии сфреры потребительского рынка и услуг в России в 2010-2016 гг. приходилась на малые предприятия (МП) (валовая добавленная стоимость).

Предприятия малого бизнеса в ссрере потребительского рынка и услуг являются экономическими системами, поэтому их можно рассматривать как социально-экономическую структуру. Как и любая экономическая структура предприятия малого бизнеса в сфрере потребительского рынка и услуг зависят от изменения различных факторов, но соответствующие институциональной среде которые способны адаптироваться к изменениям и стабильно развиваться. Так, сфрера потребительского рынка и услуг является элементом хозяйственного комплекса, она участвует в общей системе экономических отношений, подчиняется общим экономическим законам, действующим в обществе. В этой связи, на развитие малого бизнеса влияют многочисленные факторы экономического, правового, политического, социально-культурного и демографического характера.

Целью данной статьи является оценка малого бизнеса в сфере потребительского рынка и услуг как фрактора экономического роста.

Задачи статьи:

- рассмотрение социально-экономической сущности малого бизнеса в сфере потребительского рынка и услуг,

- раскрытие роли и места малого бизнеса в экономике региона;

- выявление взаимосвязи малого бизнеса и экономического роста.

Взаимосвязь малого бизнеса и экономического роста отражены в работах зарубежных авторов (М.

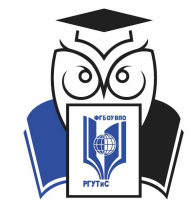

WWW.PHILOSOPH.RU 
Кочеткова Е.Н., Трусова С.В. Развитие малого бизнеса в сфере потребительского ранка и услуг как фактор экономического роста (на материалах Республики Хакасия)

Kochetkova E.N., Trusova S.V., The development of small business in the sphere of consumer market and services as a factor of economic growth (on materials of the Republic of Khakassia)

Вебер 1 , И. Маршалл², Й. Шумпетер 3 и мн. др.).

Основные аспекты избранной темы в отечественной науке были проанализированы такими учеными, как А. Афранасьев, А. Блинов, О. Русанова и мн. др. Так, О.Н. Булакина отметила, что малый бизнес является неотьемлемой частью хозяйственной системы национальной экономики. Как правило, его деятельность локализована на муниципальном и региональном уровнях организации социально-экономического пространства [5]. Д.В. Пушная в свою очередь считает, что «сфера потребительского рынка тесно связана с деятельностью всех отраслей экономики и выступает ориентиром, связующим звеном при выборе направлений развития производства и в доведении товаров и услуг до потребителя», а «торговля - это особая сфера экономики республики, которая характеризует уровень благосостояния населения и обеспечивает её социально-экономическое развитие» [12].

Объект исследования нашей статьи - малый бизнес в сфрере потребительского рынка и услуг. Предмет исследования - развитие малого бизнеса в сфере потребительского ранка и услуг как фактор экономического роста.

При написании статьи использовались методы экономико-статистической обработки, анализа и сравнения.

Научная новизна состоит в систематическом, комплексном подходе к анализу взаимосвязи малого бизнеса и экономического роста.

\section{Основная часть}

В современных условиях малый бизнес уже занял почетное место в экономике, особенно в таких секторах, как розничная торговля и услуги. Малый бизнес в сфере потребительского рынка и услуг получил наибольшее развитие в промышленных и деловых кругах, торговле и общественном питании, бытовых услугах, индустрии туризма.

Ученые-экономисты, исследователи, специалисты, правительство страны и региона активно обсуждают вопросы поддержки субъектов предпринимательства в сфере услуг путем принятия законодательных и нормативных правовых актов в целях улучшения условий в этой сфрере, разрабатываются и внедряются программы по развитию предприниматель-

\footnotetext{
${ }^{1}$ Вебер М. Избранные произведения. М.,1990. 465 с.

2 Маршалл А. Принципы экономической науки. М., 1993. 815 с.

${ }^{3}$ Шумпетер Й. «История экономического анализа. СПб., 2000. $789 \mathrm{c}$.
}

ской деятельности. Несмотря на это есть проблемы, сдерживающие развития предпринимательской деятельности в сфере потребительского рынка и услуг [4].

В данном случае человеческий потенциал малого бизнеса в сфрере потребительского рынка и услуг можно рассматривать как набор конкретных профессиональных и деловых качеств, которые позволят претендовать на должности для работы в сфере потребительского рынка и услуг, постоянно совершенствовать свои навыки [11].

Малые предприятия «гибки и ловки», они быстро могут адаптироваться к динамике изменения рынка и быстро реагировать на изменяющиеся потребности покупателей, освоение новейших технологий, внедрение инновационных методов в сфрере потребительского рынка и услуг.

Развитие «малой экономики» способствует формированию конкурентной среды. Широкое распространение «малых» компаний делает экономику более доступной для внедрения достижений научнотехнического прогресса в различных отраслях и сфеpax деятельности. Кроме того, малые предприятия эфффективно используют трудовые ресурсы и способствуют созданию новых рабочих мест, особенно в малых и средних городах как в целом в России, так и в отдельных регионах [2].

В торговле и услугах малый бизнес может быстро перейти с одних торгуемых благ и оказываемых услуг на другие, в малом производстве это выполнение рутинных функций по созданию конкретного очень ограниченного круга изделий, иногда одного и того же продукта, что делает такой малый бизнес уязвимым, менее устойчивым, зависимым от развития крупных диверсифицированных производств. При этом в отличие от крупных предприятий значительные технологические изменения в малом бизнесе крайне ограничены в силу малости масштабов фирм и контролируемых рынков.

Следовательно, развитие малого бизнеса практически всегда привязано к решению технологических задач большим бизнесом, даже несмотря на то, что часто в ряде западных стран именно малые предприятия становятся поставщиками технологических новшеств, но масштабное внедрение и тиражирование становится задачей большого бизнеса. Малый бизнес представлен в основном услугами, торговлей, посредническими операциями. Поэтому необходимо довести долю этого вида бизнеса до 40\% ВВП.

Для развития бизнеса, однако, нужны условия, включая доступ к кредитным ресурсам, и соответствующая организация внутренних

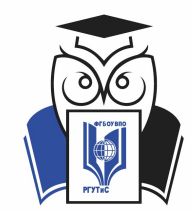

WWW.PHILOSOPH.RU 
Кочеткова Е.Н., Трусова С.В. Развитие малого бизнеса в сфере потребительского ранка и услуг как фактор экономического роста (на материалах Республики Хакасия)

Kochetkova E.N., Trusova S.V., The development of small business in the sphere of consumer market and services as a factor of economic growth (on materials of the Republic of Khakassia)

рынков. К тому же этот вид бизнеса - один из самых конкурентных. Стимулируя экономическую активность граждан, нужно уметь управлять этой конкуренцией. Данный вид конкуренции абсолютно бесперспективен относительно противостояния крупным корпорациям. Малый бизнес, за исключением отдельных случаев, обычно поигрывает в такой конкурентной борьбе по издержкам и по охвату рынка. Он развивается как вспомогательное звено крупного, иногда среднего, бизнеса, занимая определённые ниши рынка, потеря которых всё-таки не должна остановить развитие крупного производства 4 .

Отталкиваясь от сказанного, отметим два важных момента применительно к российским условиям. Малый бизнес без устойчивого развития среднего и крупного бизнеса, контролирующего хотя бы часть внутренних рынков, не будет успешен, он заполнит ниши «импортной инфраструктуры», что и наблюдалось в России в 1990-е и даже в 2000-е гг. Кстати, трудности 2015-2016 гг. в малом бизнесе связаны, в том числе и с тем, что торгово-посреднический бизнес, обслуживающий ранее импорт, стал разоряться. Причиной стала крупная девальвация, вызвавшая подорожание импортной продукции и снижение спроса на неё, а также ответные санкции России после введения западных санкций. Как видим, изменения рынка и экономической структуры подготовлены масштабными институциональными коррекциями, которых осуществлялись, в общем-то, в скоростном и мало продуманном режиме (такова специфика современного развития мировой экономики) [15].

Внутренняя экономическая политика была не в силах на них повлиять, так как эти институциональные сдвиги легли на слабости внутренней экономической структуры. Таким образом, неверные стратегические установки экономической политики, опирающиеся исключительно на частную инициативу и малый бизнес могут, на наш взгляд, негативно сказаться на будущих возможностях экономического роста, подорвать конкурентоспособность экономики в длительной перспективе. Причина состоит в игнорировании структурных и институциональных особенностей организации экономической системы, контроль внутренних рынков является ключевой позицией обеспечения экономической безопасности.

Малый бизнес в конкурентной игре, как видно было из приведенных выше данных, не может обеспечить уровень капитала и интеллекта, равнозначный

\footnotetext{
${ }^{4}$ Архангельский В.Н.«Совершенствование регулирования развития малого и среднего производственного предпринимательства: Дис. ... канд. экон. наук. Екатеринбург, 2011. 258 с.
}

транснациональным корпорациям, которые будут хорошо осваивать внутренний рынок, переориентируя на свои задачи и малый бизнес данной страны. Это обстоятельство не может не учитываться при формировании стратегии экономической политики, да ещё при враждебном окружении, когда различными экономическими методами стараются ослабить использование хозяйственного потенциала России [13].

Прежде чем сделать некоторые выводы о вкладе предприятий малого бизнеса сферы потребительского рынка и услуг в экономический рост, необходимо дать понятие экономического роста и некоторое описание состояния малого бизнеса и выделить особенности его строения.

По мнению И.Л. Любимова, экономический рост является важным условием и критерием экономического развития. Он выражается в количественном увеличении ВВП и его составляющих. Экономический рост является неким результатом хозяйственной деятельности государства, индикатором его благополучия и гарантом экономического суверенитета. Любимов отмечает, что «по параметрам устойчивости темпов экономического роста, уровню и качественному содержанию можно достаточно объективно судить об экономическом «здоровье» общества. На макроуровне важнейшими факторами экономического роста являются достижения НТП во всех отраслях и сферах экономики, создания новых высокотехнологичных производств, реструктуризации национальной экономики, понижение уровня нищеты и т.д.» [10].

Далее необходимо рассмотреть иностранный опыт развития малого бизнеса. Так, Соединенные Штаты Америки обладают крупнейшей экономикой в мире. В рейтинге стран по номинальному значению ВВП в долларовом выражении экономика США занимает лидирующее положение на протяжении нескольких десятилетий ${ }^{5}$. Ее основой является развитый сектор МСП. Из всех фирм, функционирующих на территории США, 99\% составляют малые и средние предприятия. Ежегодно они производят более половины несельскохозяйственного ВВП страны, обеспечивают порядка 50\% рабочих мест в частном секторе, представляют 98\% всех американских экспортеров, на их долю приходится 34\% экспортной выручки США'

Развитие бизнеса за рубежом идет более быстрыми темпами, поскольку национальные власти придают большое значение предприятиям малого бизнеса и оказывают им поддержку на федеральном уровне. Малый бизнес в развитых стра-

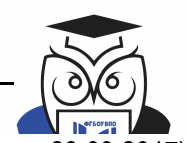

5 URL: http://www.worldbank.org (дата обращения: 23.09.2017). 6 Там же. 
Кочеткова Е.Н., Трусова С.В. Развитие малого бизнеса в сфере потребительского ранка и услуг как фактор экономического роста (на материалах Республики Хакасия)

Kochetkova E.N., Trusova S.V., The development of small business in the sphere of consumer market and services as a factor of economic growth (on materials of the Republic of Khakassia)

нах в настоящее время представляет собой средний класс, который служит базой для стабильного развития экономики. Малый бизнес в Европе составляет основу социально-экономического развития ЕС. В Евросоюзе насчитывается свыше 23 млн предприятий малого и среднего бизнеса, которые дают более половины общего оборота и добавленной стоимости. Число занятого населения в малом бизнесе Европы составляет порядка $70 \%$, или $57 \%$ общего оборота и $53 \%$ добавленной стоимости. Свыше 20 млн фрирм функционируют в США (данные без учета сельскохозяйственных структур). Примерно 5 млн фрирм - в государствах, не входящих в Европейский союз, - Канаде, Австралии, Новой Зеландии, Азии (без Японии), на Ближнем и Среднем Востоке и в Асрике, в Китае насчитывается более 4,3 млн малых и средних предприятий и 27,9 млн индивидуальных предприятий, на которых работает свыше 75\% занятого городского населения. Это составило 99\% от общего количества предприятий в стране, на которые приходится почти 60\% ВВП. Приведенные данные указывают на фундаментальную роль МП в социально-экономической и политической жизни каждой страны, т.к. в секторе МП действует подавляющее большинство предприятий, сосредоточена большая часть экономически активного населения и производится примерно половина ВВП. Так, удельный вес предприятий сектора МП в таких странах, как США, Япония, Германия, превышает 99\% от их общем количества?.

В странах Азии (Китай, Япония, Тайвань) преобладающими сферами деятельности на 2014 г. являются промышленность - $41 \%$, сельское хозяйство - $21 \%$. Но также охвачены в значительной степени и другие важные отрасли - транспорт и связь, строительство, торговля 8 .

Чтобы увидеть как развитие малого бизнеса в сфере потребительского рынка и услуг влияют на состояние экономического роста, необходимо рассмотреть состояние малого бизнеса вначале в целом по России, а затем и в регионе, в т.ч. и в сфере потребительского рынка и услуг. В России, по данным Росста-

${ }^{7}$ Сайт генерального Директората малого и среднего бизнеса, ремесленничества, услуг и свободных профессий Германии. URL:

http://www.bmwi.de/Homepae/Enlish\%20paes/The\%20ministry/DGjsp. (дата обращения: 27.06.2017).

${ }^{8}$ Сайт Министерства экономики, торговли и промышленности Японии. URL:

http.//www.meti.o.jp/enlish/other/METlintroduction/c10130ej.html (дата обращения 27.06.2017) та ${ }^{9}$, на конец 2016 г. работало около 173 тыс. МП. Отметим, что к малым относятся те, на которых занято менее 100 человек и оборот которых не превышает 800 млн рублей в год ${ }^{10}$. Наибольший процент из них (58\%) приходится на предприятия торговли и услуг по ремонту, 12\% трудятся в обрабатывающей промышленности, 10\% - в строительстве и почти 9\% занимаются недвижимостью.

Примерно такая же структура с ярко выраженным преобладанием предприятий, работающих в сфере торговли и услуг, была характерна для малого бизнеса России в 2015 г. и несколькими годами ранее, еще до начала экономического кризиса и введения антироссийских санкций.

Ясно, что предприятия торговли, недвижимости, строительства и сферы потребительского рынка и услуг не являются экспортерами и не получают валютной выручки, в тоже время большинство предприятий торговли вынуждены нести затраты в валюте, так как значительная часть потребительских товаров в России является импортированной. Поэтому неудивительно, что в 2014-2015 гг. МП несли убытки.

Так, если в 2014 г. количество МП составляло 236 тыс., а в 2015 г. увеличилось до 243 тыс., то в 2016 г. оно резко сократилось - на 29\%, до 173 тыс.

В 2016 году российский рубль укрепился к доллару на $18,6 \%$, а к евро - на 19,4\%, однако последствия его девальвации в 2014-2015 гг. сказались на сфере малого бизнеса уже в 2016 г. Многие предприятия были вынуждены уйти с рынка из-за снижения потребительского спроса и роста затрат, что было связано, в том числе и с девальвацией рубля. Совокупный оборот малых предприятий в 2016 г. сократился на 24\% к 2015 г., до 13,12 трлн рублей ${ }^{11}$.
9 Официальный сайт Федеральной службы государственной статистики. URL: http://www.gks.ru/wps/wcm/connect (дата обращения 25.06.2017).

10 Федеральный закон от 24 июля 2007 г. № 209-Ф3 «О развитии малого и среднего предпринимательства в Российской Федерации» (с изм. и доп., вступ. в силу с 01.08.2016) / Консультант Плюс.

11 Официальный сайт Федеральной службы государственной статистики. URL: http://www.gks.ru/wps/wcm/connect (дата обращения: 25.06.2017). 
Кочеткова Е.Н., Трусова С.В. Развитие малого бизнеса в сфере потребительского ранка и услуг как фактор экономического роста (на материалах Республики Хакасия)

Kochetkova E.N., Trusova S.V., The development of small business in the sphere of consumer market and services as a factor of economic growth (on materials of the Republic of Khakassia)

Российская сфрера услуг в рецессию вошла позже строительства и промышленности, однако погрузилась она в нее гораздо глубже, чем отрасли реальной экономики, - это объясняется некоторой инертностью в потребительском поведении. Большая часть российских граждан ухудшение своего материального положения из-за снижения реальных доходов и выросших цен почувствовали не сразу, и какое-то время они и дальше продолжали жить привычной жизнью - посещали салоны красоты, рестораны, продолжали путешествовать. По мере того, как начиналось «прозрение», рядовые обыватели стали все чаще включать «режим экономии», переходя на более дешевые товары быта и продукты питания, практически полностью отказываясь от являющихся необязательными услуг и откладывая покупку дорогостоящих вещей на неопределенный срок. В итоге спрос в сфрере услуг серьезно сократился - компании столкнулись со снижением количества новых заказов, причем весьма значительным [7].

В особенно сложной ситуации сейчас оказались российские компании, предоставляющие персональные и транспортные услуги, и еще один бизнестуризм.
На него негативным образом повлияли, помимо объективных экономических трудностей, еще и специфические фракторы, такие, например, как закрытие одного из основных туристических направлений массового отдыха россиян - Египет.

Далее необходимо рассмотреть, какую сегодня роль играет малый бизнес в социально-экономическом развитии Российской Федерации, в частности Республики Хакасия (PX), а также проведем анализ его состояния за последние два года.

Столица Хакасии - город Абакан. Население Республики Хакасии, по данным Росстата ${ }^{12}$, составляет 537668 человек (2017). Проблемами республики являются низкий уровень ВРП на душу населения региона, недостаточность инвестиций, недостаточно высокий уровень жизни населения, высокий износ основных фондов, недостаточный уровень развития сельского хозяйства.

Более наглядно роль малого в экономике Республики Хакасия представлена на рис. 1.

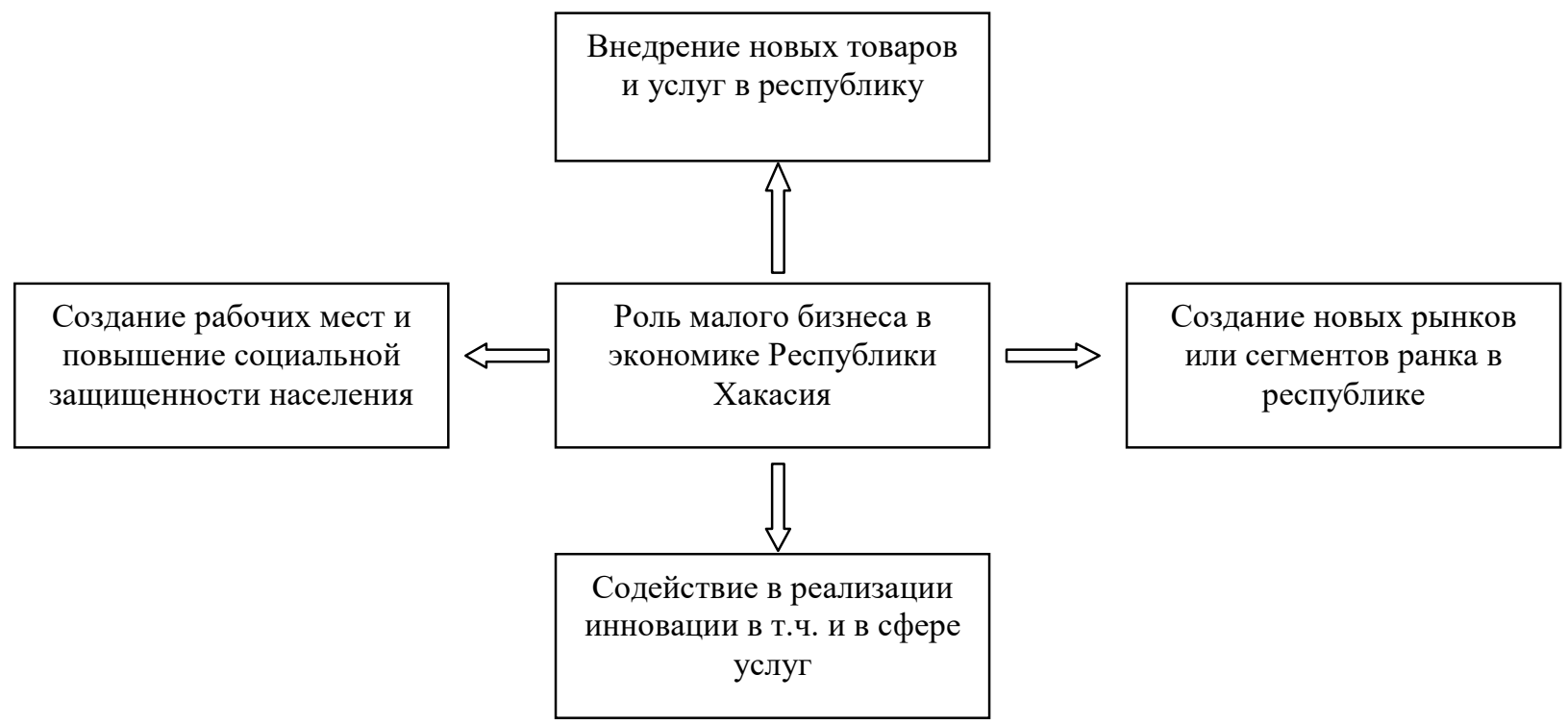

Рис. 1. Воздействие малого бизнеса на экономику региона

Fig. 1. The impact of small businesses on the regional economy

Оценка субъектов малого и среднего предпринимательства на конец 2015-2016 гг. представлена в таблице 1. 06.2017).

12 Официальный сайт Федеральной службы государственной статистики. URL: http://www.gks.ru/wps/wcm/connect (Дата обращения 
Кочеткова Е.Н., Трусова С.В. Развитие малого бизнеса в сфере потребительского ранка и услуг как фрактор экономического роста (на материалах Республики Хакасия)

Kochetkova E.N., Trusova S.V., The development of small business in the sphere of consumer market and services as a factor of economic growth (on materials of the Republic of Khakassia)

\section{Оценка субъектов малого и среднего предпринимательства на конец 2015-2016 гг.}

\section{Таблица 1}

The rating of subjects of small and medium business at the end of 2015-2016

Table 1

\begin{tabular}{|c|c|c|c|}
\hline \multirow{2}{*}{ Наименование показателей } & \multicolumn{2}{|c|}{ На конец года } & \multirow{2}{*}{$\begin{array}{c}\text { Отклонение } \\
(+;-)\end{array}$} \\
\hline & 2015 год & 2016 год & \\
\hline $\begin{array}{l}\text { Субъекты малого и среднего предпринимательства всего: } \\
\text { Зарегистрированные индивидуальные предприниматели, } \\
\text { (в т.ч. главы крестьянских (фермерских) хозяйств), человек }\end{array}$ & $\begin{array}{l}22610 \\
15766\end{array}$ & $\begin{array}{l}22551 \\
15425\end{array}$ & -59 \\
\hline $\begin{array}{l}\text { Малые предприятия (в т.ч. микропредприятий), единиц } \\
\text { Средние предприятия (далее СП), ед. }\end{array}$ & $\begin{array}{c}6795 \\
49\end{array}$ & $\begin{array}{c}7071 \\
55\end{array}$ & $\begin{array}{c}276 \\
6\end{array}$ \\
\hline $\begin{array}{l}\text { Оборот розничной торговли малых предприятий (без микропред- } \\
\text { приятий), млн рублей }\end{array}$ & 6703,52 & 4604,22 & $-2099,3$ \\
\hline Оборот средних предприятий, млн рублей, всего & 11977,04 & 15624,94 & 3647,9 \\
\hline
\end{tabular}

По данным Хакасстата ${ }^{13}$, в 2016 г. осуществляют деятельность 7071 МП (в том числе микропредприятий), что на 276 больше чем в 2015 г., 55 средних (их число увеличилось по отношению к 2015 г. на 6 единиц).
Количество субъектов предпринимательства республики Хакасия снизилось на 59 единиц и составило 22551 единицу, отрицательная динамика отражена на puc. 2.

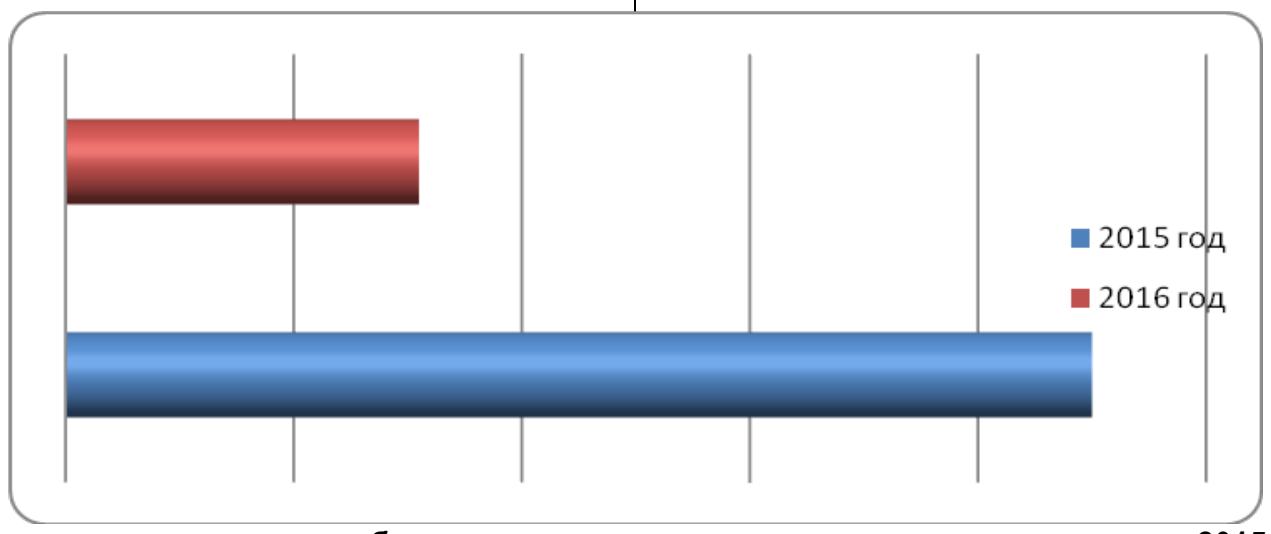

Рис. 2. Изменение количества субъектов малого и среднего предпринимательства в 2015-2016 гг. Fig. 2. The quantity change of small and medium business in 2015-2016

Оборот малых предприятий составил в 2016 г. 23 905,91 млн рублей, наблюдается снижение в объеме 2 571,03 млн рублей по сравнению с 2015 г. Численность занятых в малом и среднем предпринимательстве (бизнесе) в 2016 г. по отношению к 2015 г. сократилось на 9,33 тыс. человек. ${ }^{14}$ Если сравнить с МП в целом по России, то можно отметить, что малый бизнес в России превращен в фантом.
На рынке действуют фирмы-однодневки и те, кто функционирует только на бумаге. Благодаря этому статистика по числу субъектов малого и среднего бизнеса (МСБ) растет. Но численность занятых в малом бизнесе сокращается, что только доказывает, что малый бизнес в России официальный - это фикция, а реальный все больше предпочитает уходить в тень от всевидящего ока чиновников и силовых структур. На рисунке 3 представлен оборот МП по Республике Хакасия.

13 Территориальный орган федеральной службы государственной статистики по Республике Хакасия, статистические данные [Электронный ресурс]. http://hakasstat.gks.ru»(дата обращения:»15.07.2017).

${ }^{14}$ Малые предприятия // Территориальный орган Федеральной службы государственной статистики по Республике Хакасия (Хакасстат). URL: http : // hakasstat . gks.ru/ wps/ wcm / connect / rosstat_ts / hakasstat/resources/a985d8804e81de85b3adf30d534aab22/ \%D0\%9C\%D0\%9F2\%D0\%BA\%D0\%B2.htm» (дата обращения: 11.01.2017). 
Кочеткова Е.Н., Трусова С.В. Развитие малого бизнеса в сфере потребительского ранка и услуг как фактор экономического роста (на материалах Республики Хакасия)

Kochetkova E.N., Trusova S.V., The development of small business in the sphere of consumer market and services as a factor of economic growth (on materials of the Republic of Khakassia)

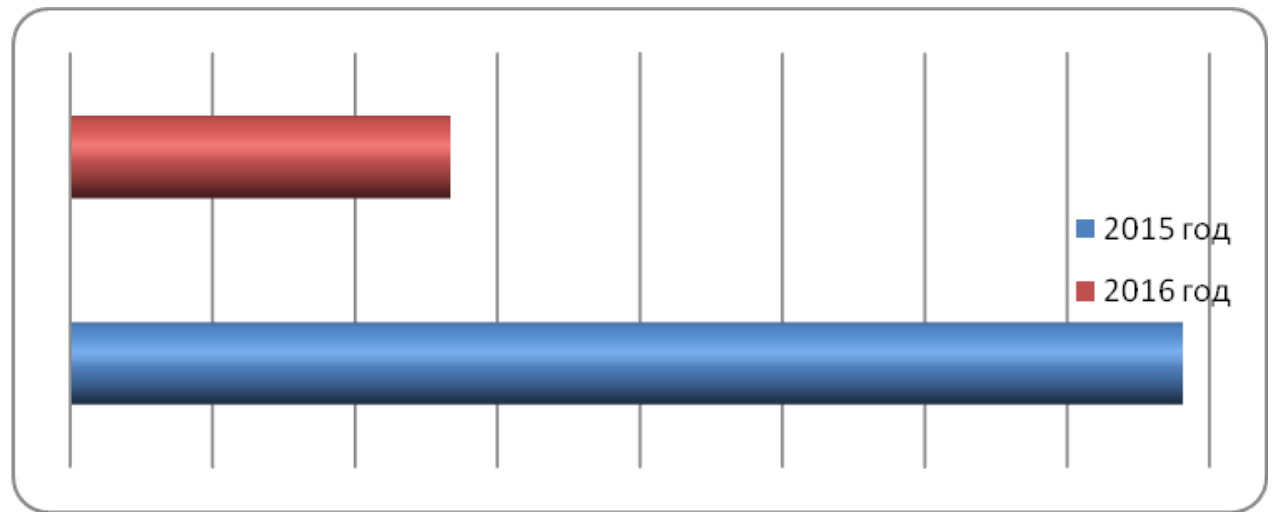

Рис. 3. Оборот малых предприятий (без микропредприятий) в 2015-2016 гг.

Fig. 3. The circulation of small enterprises (without microenterprises) in 2015-2016

Снижение оборота малых предприятий связано с общим спадом деловой активности.
Оборот розничной торговли на конец 2016 года составил 4 604,22 млн рублей, что меньше аналогичного показателя 2015 года на 2 099,3 млн рублей данные представлены на рис. 4.

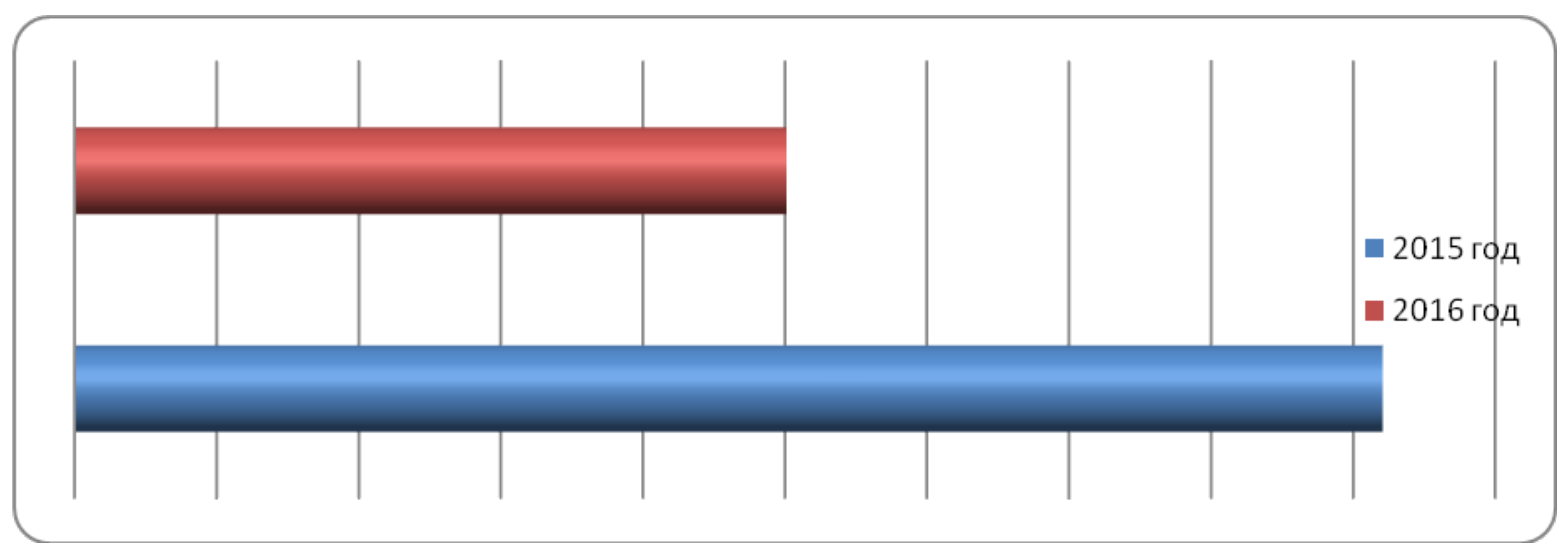

Рис. 4. Оборот розничной торговли МП (без микропредприятий), млн рублей 15

Fig. 4. Retail trade circulation of small enterprises (without micro-enterprises), million rubles

По данным рис. 4, одной из причин снижения оборота розничной торговли связано с сокращением реальных доходов населения Республики. Реальные располагаемые доходы населения упали на $3,0 \%$ по сравнению с соответствующим периодом 2015 г. [5].

Сфрера торговли и общественного питания в связи с достаточно высокой оборачиваемостью капитала является наиболее предпочтительной для малого бизнеса по Республике Хакасия.
По оценочным данным 2016 г., её удельный вес составил $37,93 \%$ в общем количестве МП (без микропредприятий) республики.

15 Территориальный орган федеральной службы государственной статистики по Республике Хакасия, статистические данные [Электронный ресурс]. http://hakasstat.gks.ru»(дата обращения:»15.07.2017). 
Кочеткова Е.Н., Трусова С.В. Развитие малого бизнеса в сфере потребительского ранка и услуг как фрактор экономического роста (на материалах Республики Хакасия)

Kochetkova E.N., Trusova S.V., The development of small business in the sphere of consumer market and services as a factor of economic growth (on materials of the Republic of Khakassia)

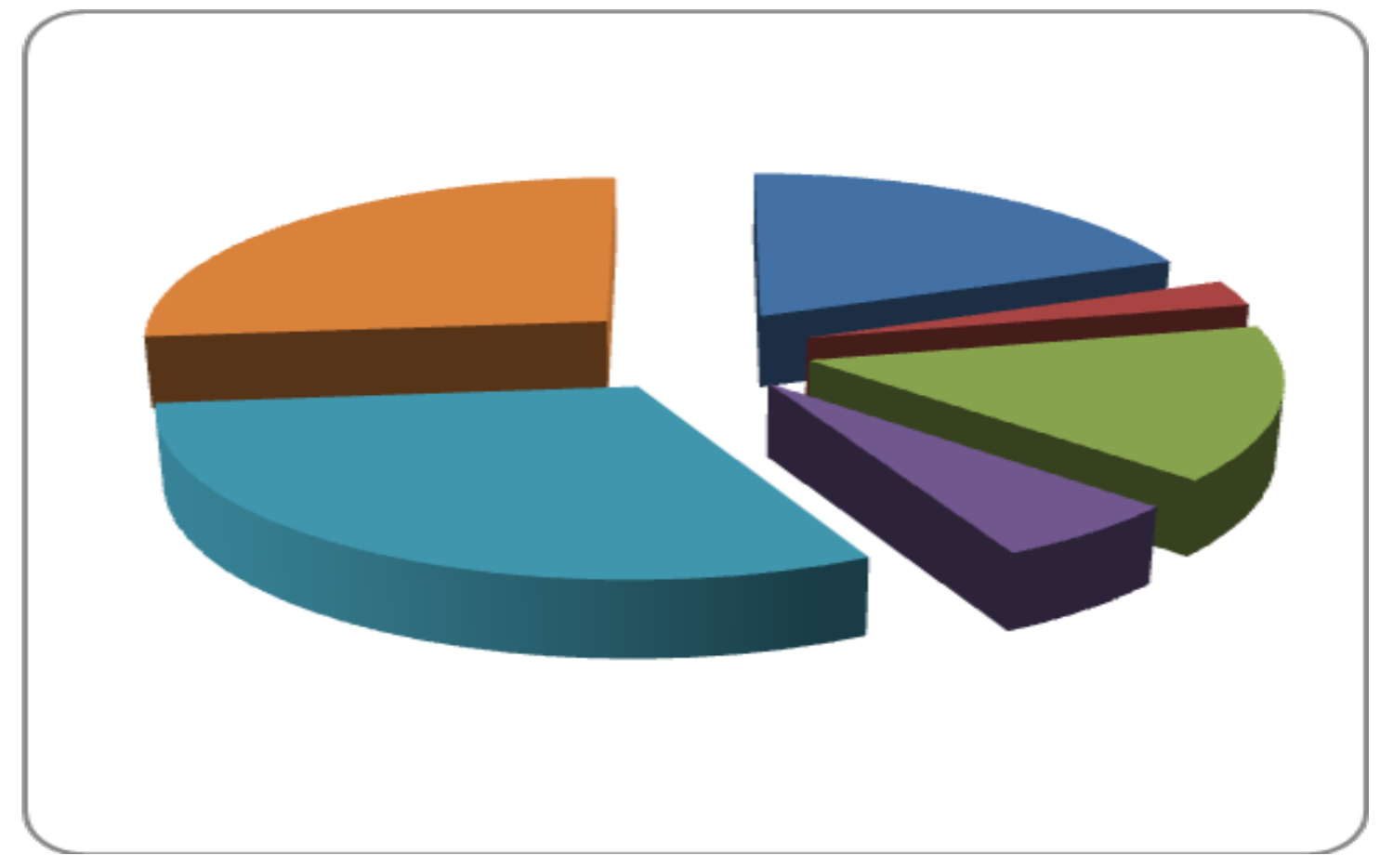

Рис. 5. Отраслевая структура по видам экономической деятельности за 2015-2016 гг.

Fig. 5. Sectoral structure by type of economic activities in 2015-2016

Если рассматривать численность занятых в малом бизнесе по Республике Хакасия за 2016 г., она составила 39,72 тыс. человек, без учета работающих на индивидуальных предпринимателей, что ниже аналогичного показателя 2015 г. на 9,33 тыс. человек (49,05 тыс. человек за 2015 г.).

Тремя ключевыми видами услуг за 2015 г. от всего объема оказываемых населению платных услуг в республике Хакасия являются жилищно-коммунальные услуги, транспортные услуги и услуги связи. На их долю в целом приходилось 55,4\% общего объема платных услуг. В структуре платных услуг населению наибольший удельный вес приходится на долю коммунальных услуг $(23,8 \%)$, услуг связи $(20,9 \%)$, бытовых услуг (11,8\%), транспортных услуг $(11,8 \%)$. На 40,2 млрд рублей оказано платных услуг населению Республики Хакасия в 2016 г., или 98,4\% к 2015 г. 16

Если рассматривать структуру платных услуг, то в 2016 г. преобладали транспортные услуги, услуги связи и коммунальные услуги. На их долю в целом прихо-

${ }^{16}$ Аналитическая записка о состоянии малого и среднего предпринимательства в Республике Хакасия и о мерах поддержки по итогам 2016 года. Официальный портал Правительства Республики Хакасия: [Электронный ресурc]. URL: http://r19.ru/authorities/ (дата обращения: 20.06.2017). дилось 54,4\% общего объема платных услуг. В декабре 2016 г. в структуре объема бытовых услуг преобладали услуги по ремонту и строительству жилья и других построек и ритуальные услуги, занимая $24,7 \%$ и 20,9\%, соответственно.

Объем платных услуг в Республике Хакасия сократился. Особенно сильное падение наблюдается в предоставлении туристских услуг в республике. В период кризиса население Республики экономит на услугах туроператоров, самостоятельно планируя поездки. Естественной (и полезной) стороной кризиса внешнего туризма стало увеличение внутреннего туризма в республике Хакасия.

Росту доли платных услуг в расходах населения в период кризиса способствуют не только относительно низкие возможности конкуренции в этой сфере (получение качественных услуг за более низкую цену часто связано с дополнительными затратами времени на анализ большого числа альтернативных предложений и, что немаловажно, с нарушением привычек - например, при смене школы или врача), но и инерционная специфика ценообразования на них. Цены на услуги для населения реагируют на трудности в экономике России более плавно (их прирост замедляется) и с некоторым отста-

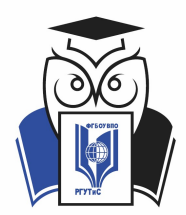

WWW.PHILOSOPH.RU 
Кочеткова Е.Н., Трусова С.В. Развитие малого бизнеса в сфере потребительского ранка и услуг как фрактор экономического роста (на материалах Республики Хакасия)

Kochetkova E.N., Trusova S.V., The development of small business in the sphere of consumer market and services as a factor of economic growth (on materials of the Republic of Khakassia)

ванием по сравнению с ценами на товары. Малые предприятия Республики Хакасия, в том числе и в сфере потребительского рынка услуг, показывают снижение темпов экономического роста по основным показателям деятельности, хотя по ряду показателей сохраняется положительная динамика. Снижение свя- зано с экономическим спадом в целом. Для запуска экономического роста требуются большие инвестиции и самое главное - стимулирование спроса, которое способно поддержать выбытие так называемых старых технологий [10].

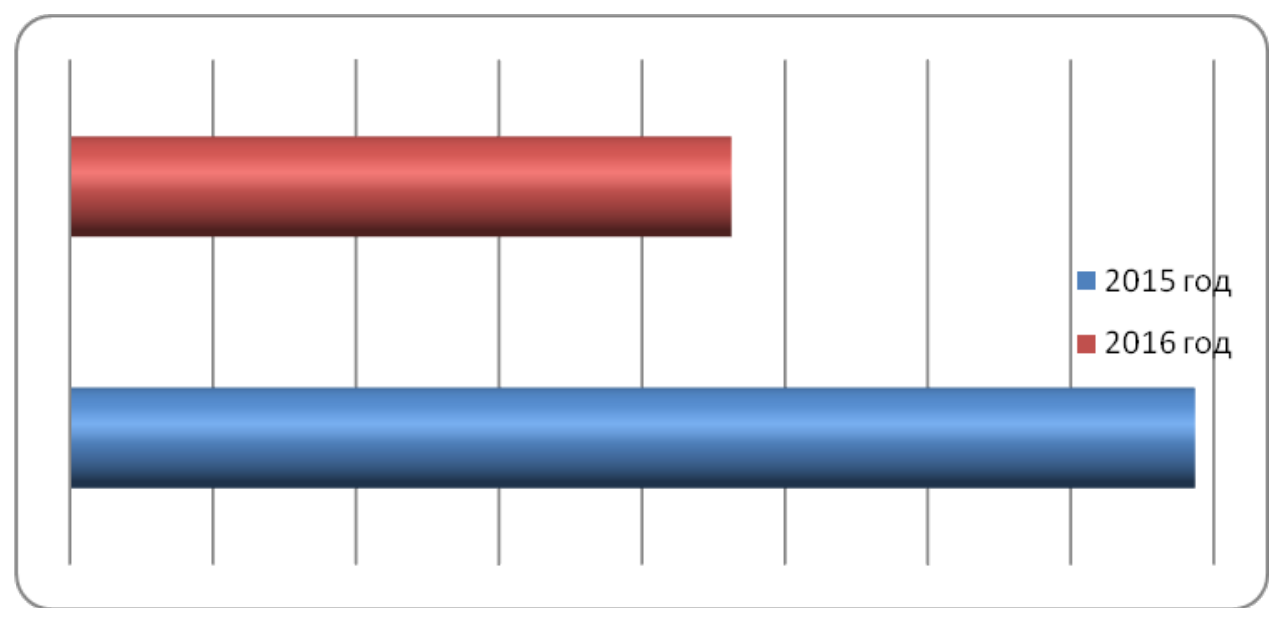

Рис. 6. Объем инвестиций в основной капитал малых предприятий по Республике Хакасия в 2015-2016 гг. ${ }^{17}$ Fig. 6. The volume of investments into fixed capital of small enterprises in the Republic of Khakassia in the period of 2015-2016

17 Территориальный орган федеральной службы государственной статистики по Республике Хакасия, статистические данные [Электронный ресурс]. Режим доступа: http://hakasstat.gks.ru»(дата обращения:»15.07.2017). 
Кочеткова Е.Н., Трусова С.В. Развитие малого бизнеса в сфере потребительского ранка и услуг как фактор экономического роста (на материалах Республики Хакасия)

Kochetkova E.N., Trusova S.V., The development of small business in the sphere of consumer market and services as a factor of economic growth (on materials of the Republic of Khakassia)

Приток инвестиций в основной капитал малых предприятий за 2016 г. составил 46260 тыс. рублей (рис. 6). ${ }^{18}$ Наблюдается значительное снижение инвестиций по сравнению с 2015 г. на 32 423,9 тыс. рублей (в 2015 г. составлял 78 683,9 тыс. рублей).

Таким образом, мы видим, что малые предприятия Республики Хакасия продемонстрировали замедление темпов экономического роста по ключевым показателям, хотя некоторые показатели продолжили положительную динамику. Замедление темпов роста в развитии малых предприятий связано и с небольшими инвестициями в этой сфрере, а также тем, что данный вид бизнеса является торгово-посредническим.

Отраслевая структура субъектов малого предпринимательства Республики Хакасия уже на протяжении многих лет не изменяется. Торговля, общественное питание, услуги остается более привлекательными отраслями, чем производственная отрасль в Республике. Возникает ситуация, когда развитие субъектов малого предпринимательства, особенно в сфере производства и инновационной деятельности, возможно только посредством активной целенаправленной поддержки. Одно из приоритетных направлений в развитии общественного питания - это открытие предприятий питания для молодежи и детей.
Если рассматривать развитие малого бизнеса и его поддержку то можно отметить, что в 2017 г. запланировано внедрение «Бизнес-навигатора МСП» на территории Республики Хакасия ${ }^{19}$.

В 2017 году будет открыт первый в республике детский технопарк «Кванториум». Республиканский технопарк откроет свои двери для детей в возрасте от 5 до 18 лет обучение будет проходить на бесплатной основе.

Здесь начинающие специалисты смогут узнать, как работать на новейших машинах, использовать квадрокоптеры для создания собственных роботов и мн. др. Ведутся работы по открытию индустриального парка «Черногорский» ${ }^{20}$. Продолжается работа по дальнейшему формированию сети быстрого питания доступных для среднего класса населения и различающихся формой обслуживания, пропускной способностью и ценовой доступностью.

Деятельность предприятий общественного питания обеспечивает занятость население, независимо от возрастных категорий и уровня профессионального образования, поэтому развитие этого направления потребительского рынка может способствовать снижению уровня безработицы в республике.

18 Постановление правительства Республики Хакасия от 01.11.2016 № 530 Об утверждении государственной программы Республики Хакасия «Экономическое развитие и повышение инвестиционной привлекательности Республики Хакасия (2017-2021 годы)»

${ }^{19}$ Аналитическая записка о состоянии малого и среднего предпринимательства в Республике Хакасия и о мерах поддержки по итогам 2016 г. Официальный портал Правительства Республики Хакасия: [Электронный ресурc]. URL: http://r-19.ru/authorities/ (дата обращения: 20.06.2017).

${ }^{20}$ Аналитическая записка о состоянии малого и среднего предпринимательства в Республике Хакасия и о мерах поддержки по итогам 2016 г. Официальный портал Правительства Республики Хакасия: [Электронный ресурc]. URL: http://r-19.ru/authorities/ (Дата обращения 20.06.2017). 
Кочеткова Е.Н., Трусова С.В. Развитие малого бизнеса в сфере потребительского ранка и услуг как фактор экономического роста (на материалах Республики Хакасия)

Kochetkova E.N., Trusova S.V., The development of small business in the sphere of consumer market and services as a factor of economic growth (on materials of the Republic of Khakassia)

В структуре платных услуг по-прежнему около 67\% всего объема приходится на услуги жилищнокоммунального комплекса, транспорта и связи.

В 2017 году в сфере потребительского рынка в Республике Хакасия будет продолжена работа:

- по повышению эффрективности государственно-

го регулирования внутренней торговли;

- развитию инфраструктуры торговли;

- развитию торговли в малых и отдаленных населенных пунктах республики;

- снижению кадрового дефицита;

- обеспечению необходимого уровня конкуренции;

- развитию новых форматов в торговле.

Потребительский рынок Хакасии - самый динамичный сектор, который быстро растёт. Этому направлению просто необходим стратегический план развития, т.е. потребительский рынок Хакасии - это своего рода стратегический приоритет ${ }^{21}$.

Несмотря на продолжающиеся и предстоящие важные изменения в сфере малого бизнеса в позитивном ключе, остаются нерешенные вопросы.

Рассматривая экономическую политику в целом, мы можем отметить, что ошибочные стратегические цели экономической политики, которая опирается исключительно на частную инициативу и малый бизнес, на наш взгляд, окажет негативное влияние на будущие возможности для экономического роста, что подрывает конкурентоспособность экономики в долгосрочной перспективе [8].

В 2017 году на российскую экономику в целом и на малый бизнес, на наш взгляд, влияют те же негативные фракторы, которые действуют на протяжении последних нескольких лет:

- нет реформ и стратегии преобразований в стране и в регионе;

- санкции ограничивают экономический рост;

- низкие цены на нефть.

Поэтому перед властью, как и в предыдущий 2015 г., остро будет стоять вопрос наполнения бюджета: объемы добычи нефтти сократятся, если рост цен на нефть и будет, то весьма незначительный, бюджет будет нуждаться в новых источниках дохода, которые правительство рассчитывает получить за счет населения. Поэтому 2017 г. станет очередным периодом застойных явлений в российской экономике.

Надо разделить два основных направления воздействия на малый бизнес, чтобы увеличить экономический рост - прямое и косвенное: прямое - это раз-

21 Закон Республики Хакасия от 01.07.2011 № 60-3РХ «О государственном регулировании торговой деятельности в Республике Хакасия». витие структур малого бизнеса, и напрямую увеличить ВВП страны (экономический рост), так и косвенные эфффекты - рост ВВП за счет взаимодействия малого бизнеса с крупными и средними (научно-технического развития) [6].

Перечень задач фрормирования малого бизнеса диктуется каждым видом деятельности в отдельности. Создавать искусственные стимулы для развития малого бизнеса, представляя эту задачу в виду крайне необходимой без должных на то оснований и ресурсов, является крайне нецелесообразным вариантом проводимой политики стимулирования. После анализа полученных данных о состоянии малого бизнеса и его динамики развитии в России вообще и Республике Хакасия в частности можно сделать следующий небольшой вывод: нет необходимости абсолютизировать влияние и перспективу малого бизнеса в свете новой модели экономического роста, поскольку эта модель не предполагает создание режима динамики на услугах. Тогда как стоящие задачи развития требуют развёртывания крупного бизнеса, значит, и малый бизнес будет претерпевать изменения.

Однако объективно существуют внутренние проблемы развития малого бизнеса в сфрере потребительского рынка и услуг, к ним можно отнести следующие:

- низкий уровень социально-экономического развития региона в целом;

- низкий уровень жизни населения;

— неконкурентоспособность продукции и услуг;

- неблагоприятный инвестиционный климат в регионе;

- устаревание основных фондов;

- дефицит республиканского бюджета и полная финансовая зависимость от поступлений из федерального центра.

Серьезными проблемами остаются недостаток и противоречивость законодательных актов РФ, их неадаптированность к фрункционированию экономики республики, отсутствие механизма реализации прав, полномочий и ответственности управленческих структур на высшем уровне, отсутствие рациональной системы управления предпринимательской деятельностью в сфрере потребительского рынка и услуг.

\section{Заключение}

Анализ приведенных данных по малому бизнесу и его структуре приводит к следующим выводам:

- малый бизнес является в основном торгово-посредническим, обеспечивает предоставление различных услуг;

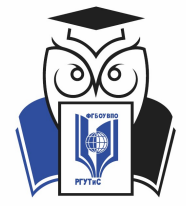

WWW.PHILOSOPH.RU 
Кочеткова Е.Н., Трусова С.В. Развитие малого бизнеса в сфере потребительского ранка и услуг как фактор экономического роста (на материалах Республики Хакасия)

Kochetkova E.N., Trusova S.V., The development of small business in the sphere of consumer market and services as a factor of economic growth (on materials of the Republic of Khakassia)

- в кризисные 2015-2016 гг. оборот организаций малого бизнеса снижается. Сфера торговли и общественного питания, в связи с достаточно высокой оборачиваемостью капитала, является наиболее предпочтительной для малого бизнеса. По итогам 2016 г. её удельный вес составил $28,51 \%$ в общем количестве малых предприятий (без микропредприятий) республики. На втором месте - предприятия промышленности, которые составляют 20,39\%, на третьем - строительство (13,38\%), транспорт и связь - 6,36\%, сельское хозяйство - $3,07 \%$, на прочие $-28,29 \%$;

- решение задачи реструктуризации малого бизнеса должно готовиться в рамках общей структурной политики, а сам такой бизнес стимулироваться в каждом конкретном виде деятельности и определяться его состоянием и перспективами развития.

Слабое развитие малого бизнеса в Российской Федерации в общем и в частности в Республики Хакасия, а также малая степень освещенности этой проблемы приводит к актуальности оценки роли малого бизнеса в ситуации в стране в целом. Проблему необходимо решать посредством более глубокого научного исследования, принятия мер непосредственно со стороны государства. Чтобы достичь высокого уровня развития малого бизнеса, необходимо осуществить ряд мероприятий.

1. Сформировать инфрраструктуру поддержки и развития малого предпринимательства.

2. Создать льготные условия использования субъектами малого предпринимательства государственных финансовых, информационных и материально-технических ресурсов, а также использование технологий и научно-технических разработок.

3. Установить упрощенный порядок регистрации субъектов малого предпринимательства, сертификации их продукции, предоставление лицензий на их вид деятельности, государственной статистической и бухгалтерской отчетности.

4. Организовать подготовку, переподготовку и повышение квалификации кадров для малых предприятий.

5. Поддерживать внешнеэкономическую деятельность субъектов малого предпринимательства, в том числе развитие их торговых, научно-технических, производственных, информационных связей с зарубежными государствами.

Развитие малого бизнеса способно ускорить восстановление экономики России при условии дальнейшей поддержки со стороны государства. Кроме того, с помощью предпринимателей удастся создать новые рабочие места, что существенно улучшит ситуацию на рынке труда. Социально-экономические реформы, которые проводятся в России, очень нужны. Поддержка малого бизнеса является одной из приоритетных задач правительства. Для достижения этой цели используется широкий арсенал инструментов. Важное значение имеет государственная поддержка, которая должна включать в себя нормативно-правовое обеспечение, инфраструктурное обеспечение, ресурсное обеспечение, кадровое обеспечение и др. При этом осуществление мер государственной поддержки малого предпринимательства должно соответствовать принципам протекционизма, дифференцированности, селективности, обусловленной гарантированности и ответственности, проводиться с применением программно-целевого подхода и учитывать динамичность и противоречивость процесса становления малого предпринимательства [15].

Кризисные явления в экономики стали испытаниями для малого бизнеса. Рост кредитных ставок, девальвация рубля и стремительное падение доходов населения отразились на финансовом положении малого бизнеса. В 2017 году чиновники прогнозировали улучшение экономической ситуации, однако динамика нефртяного рынка внесла свои коррективы.

Малый бизнес как элемент национальной экономики обладает огромным потенциалом, использование которого может стать мощным ресурсом в решении тактических задач социально-экономических преобразований, помочь уже в среднесрочной перспективе наиболее эфффективно достичь целей экономического роста. Вопрос развития малого бизнеса в сфрере потребительского рынка и услуг как фрактора экономического роста является важным для республики и затрагивает десятки тысяч жителей Республики Хакасии.

\section{Литература:}

1. Асаул А.Н. Организация предпринимательской деятельности // Международный журнал прикладных и фундаментальных исследований. 2013. № 2. С. 104-105

2. Аганбегян А.Г. Сокращение инвестиций - гибель для экономики, подъём инвестиций её спасение // Экономические стратегии. 2016. № 4. С. 74-83.

3. Афанасьев В.С. Малый бизнес: проблемы становления // Российский экономический журнал. 1993. № 2. С. 1-16.

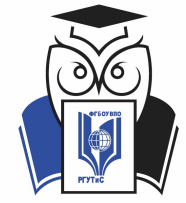

WWW.PHILOSOPH.RU 
Кочеткова Е.Н., Трусова С.В. Развитие малого бизнеса в сфере потребительского ранка и услуг как фактор экономического роста (на материалах Республики Хакасия)

Kochetkova E.N., Trusova S.V., The development of small business in the sphere of consumer market and services as a factor of economic growth (on materials of the Republic of Khakassia)

4. Гайсина А.Р., Артемов Н.И. Современные проблемы развития предпринимательской деятельности в ссрере услуг // Современные проблемы науки и образования. 2015. № 1-1. URL: https://scienceeducation.ru/ru/article/view?id=18553 (дата обращения: 18.07.2017).

5. Булакина О.Н. Основные проблемы малого и среднего бизнеса // Социально-экономические проблемы развития Саяно-Алтая: прил. к «Вестнику КрасГАУ»: сб. науч. тр. Вып. 7. Красноярск. 2012. С. 99-102.

6. Казыханов Р.Р. Анализ современного состояния и тенденций развития малого и среднего предпринимательства в структуре региональной промышленности // Предпринимательство. 2014. № 12. С. 211-218.

7. Кочеткова Е.Н. Оценка субъектов малого предпринимательства в Республике Хакасия // Молодой ученый. 2016. № 29. С. 428-431.

8. Лаврова Е.В. Совершенствование методологии разработки региональных программ поддержки малого и среднего предпринимательства как стратегического ресурса регионального экономического роста // Наука и бизнес: пути развития. 2015. № 6 (48). С. 138-140.

9. Ларионова Г.Н. «Современное состояние и тенденции развития малого бизнеса в Российской Федерации // Научное обозрение. 2015. № 18. С. 321-323.

10. Любимов И.Л. Неравенство и экономический рост: вызовы для российской экономики // Российское предпринимательство. 2016. Том 17. № 1. с. 11-22.

11. Макконнелл К., Брю С. Экономика: принципы, проблемы и политика. М: Высшее образование, 2009.

12. Омарова К.А. Развитие малого и среднего бизнеса в сфере услуг как фрактор экономического роста // Проблемы современной экономики. 2011. № 3 (39). С. 153-162.

13. Сороков Т.Х. Экономические противоречия в сфрере социальных услуг // Экономические науки. 2011. № 85. C. $190-194$.

14. Сухарев О.С. Экономический рост в России: роль малого бизнеса // Экономика и предпринимательство. № 1 (78). 2017. С. 372-379.

15. Хабыев Я. Малый бизнес - факторы роста и развития // Молодой ученый. 2014. №11.»С. 238-242.

\section{References:}

1. Asaul A.N., Organization of the business. Mezhdunarodnyi zhurnal prikladnykh i fundamental'nykh issledovanii, no. 2, 2013, pp. 104-105. (In Russ.).

2. Aganbegyan A.G., Reduction of Investments - the Death of the Economy, Investment Growth - its Salvation. Ekonomicheskie strategii, no. 4, 2016, pp. 74-83. (In Russ.).

3. Afanas'ev B.C., Small business: problems of formation. Rossiiskii ekonomicheskii zhurnal, no. 2, 1993, pp. 116. (In Russ.).

4. Gaisina A.R., Artemov N.I., Modern problems of development of business activity in the services sector. Sovremennye problemy nauki i obrazovaniya, no. 1-1, 2015. (In Russ.) Available at: https://scienceeducation.ru/ru/article/view?id=18553 (Accessed on July 18, 2017).

5. Bulakina O.N., The main problems of small and medium business. Sotsial'no-ekonomicheskie problemy razvitiya Sayano-Altaya: pril. k «Vestniku KrasGAU»: sbornik nauchnykh trudov, no. 7, 2012, pp. 99-102. (In Russ.)

6. Kazykhanov R.R., Analysis of the current status and trends of small and medium enterprises in the structure of the regional industry. Predprinimatel'stvo, no. 12, 2014, pp. 211-218. (In Russ.).

7. Kochetkova E.N., The rating of subjects of small entrepreneurship in the Republic of Khakassia. Molodoi uchenyi, no. 29, 2016, pp. 428-431. (In Russ.).

8. Lavrova E.V., Improving the Methodology of Planning of Regional Programs of Support for Small and Medium Businesses as a Strategic Resource for Regional Economic Growth. Nauka i biznes: puti razvitiya, no. 6 (48), 2015, pp. 138-140. (In Russ.).

9. Larionova G.N., Current status and development trends of small business in the Russian Federation. Nauchnoe obozrenie, no. 18, 2015, pp. 321-323. (In Russ.).

10. Lyubimov I.L., Inequality and economic growth: challenges for the Russian economy. Rossiiskoe predprinimatel'stvo, vol. 17, no. 1, 2016, pp. 11-22. (In Russ.).

11. McConnell C.R., Brue S., Economics: principles, problems and policies. Moscow: Vysshee obrazovanie, 2009. (In Russ.).

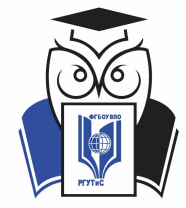


Кочеткова Е.Н., Трусова С.В. Развитие малого бизнеса в сфере потребительского ранка и услуг как фактор экономического роста (на материалах Республики Хакасия)

Kochetkova E.N., Trusova S.V., The development of small business in the sphere of consumer market and services as a factor of economic growth (on materials of the Republic of Khakassia)

12. Omarova K.A., Development of small and medium businesses in the service sector as a factor of economic growth. Problemy sovremennoi ekonomiki, no. 3 (39), 2011, pp. 153-162. (In Russ.).

13. Sorokov T.Kh., Economic contradictions in the sphere of social services. Ekonomicheskie nauki, no. 85, 2011, pp. 190-194. (In Russ.).

14. Sukharev O.S., Economic growth in Russia: role of small business. Ekonomika i predprinimatel'stvo, no. 1 (78), 2017, pp. 372-379. (In Russ.).

15. Khabyev Ya., Small business - growth factors and development. Molodoi uchenyi, no. 11, 2014, pp. 238-242. (In Russ.). 